\title{
Serum L-Homoarginine Concentration is Elevated During Normal Pregnancy and is Related to Flow-Mediated Vasodilatation
}

\author{
Pirjo Valtonen, LicPhil; Tomi Laitinen, PhD*; Tiina Lyyra-Laitinen, $\mathrm{PhD} *$; \\ Olli T. Raitakari, $\mathrm{PhD}^{\dagger}$; Markus Juonala, $\mathrm{PhD}^{\dagger \dagger}$; Jorma SA Viikari, $\mathrm{PhD}^{\dagger \dagger}$; \\ Nonna Heiskanen, $\mathrm{PhD}^{* *}$; Esko Vanninen, $\mathrm{PhD} *$; \\ Kari Punnonen, $\mathrm{PhD}$; Seppo Heinonen, $\mathrm{PhD}^{* *}$
}

\begin{abstract}
Background Normal pregnancy is associated with enhanced vasodilatation because of the increased nitric oxide (NO) production. Because L-homoarginine can act as a substrate for NO production, concentrations of L-homoarginine in normal pregnancy were assessed in the present study to test whether L-homoarginine is associated with endothelial function.

Methods and Results Healthy non-pregnant $(\mathrm{n}=61)$ and pregnant women $(\mathrm{n}=58)$ were studied in a cross-sectional study. L-homoarginine, L-arginine, asymmetric dimethylarginine and symmetric dimethylarginine concentrations were determined simultaneously by high-performance liquid chromatography. Endothelium-dependent brachial artery flow-mediated dilation (FMD) was measured by ultrasound. The serum L-homoarginine concentration was significantly higher during the second and the third trimesters compared with the levels in the nonpregnant women $(4.8 \pm 1.7$ and $5.3 \pm 1.5$ vs $2.7 \pm 1.0 \mu \mathrm{mol} / \mathrm{L}, \mathrm{p}<0.001$, respectively). In line with this, FMD increased in response to pregnancy $(\mathrm{p}<0.05)$. Three months after delivery, the L-homoarginine concentrations and FMD were comparable to those recorded in the non-pregnant females. The concentration of L-homoarginine correlated significantly with gestational age $(\mathrm{r}=0.426, \mathrm{p}=0.001)$ and brachial artery diameter and $\mathrm{FMD}(\mathrm{r}=0.362, \mathrm{p}=0.006$ and $\mathrm{r}=0.306, \mathrm{p}=0.022$, respectively) in pregnancy.

Conclusions L-homoarginine appears to be increased during the second and third trimesters of pregnancy and may contribute to the enhanced endothelial function in normal pregnancies. (Circ J 2008; 72: 1879-1884)

Key Words: Asymmetric dimethylarginine (ADMA); Flow-mediated vasodilatation; L-homoarginine; Nitric oxide; Pregnancy
\end{abstract}

I recent years, assessment of endothelial function by non-invasive brachial artery flow-mediated dilatation $(\mathrm{FMD})^{1}$ technique has been widely used in cardiovascular research ${ }^{2-6}$ FMD is enhanced throughout the pregnan$\mathrm{cy}^{7}$ because of increased nitric oxide (NO) production.

Normal pregnancy is associated with profound hemodynamic changes that include enhanced vasodilatation? The enzyme, NO synthase (NOS, EC 1.14.13.39), and its competitive inhibitor, asymmetric dimethylarginine (ADMA), are suggested to represent a regulatory pathway, whereas symmetric dimethylarginine (SDMA), a stereoisomer of ADMA, does not directly inhibit NOS. In a normal pregnancy, ADMA levels are decreased in comparison with the levels found in non-pregnant females ${ }^{10}$ Furthermore, it has

(Received March 20, 2008; revised manuscript received May 20, 2008; accepted June 12, 2008; released online September 18, 2008) Laboratory Centre, Department of Clinical Chemistry, *Department of Clinical Physiology and Nuclear Medicine, **Department of Obstetrics and Gynaecology, Kuopio University Hospital and University of Kuopio, Kuopio, Departments of Clinical Physiology and ItIternal Medicine, Turku University Hospital and University of Turku, Turku, Finland

Mailing address: Seppo Heinonen, PhD, Department of Obstetrics and Gynaecology, Kuopio University Hospital, PO Box 1777, FIN-70211 Kuopio, Finland. E-mail: seppo.heinonen@kuh.fi

All rights are reserved to the Japanese Circulation Society. For permissions, please e-mail: cj@j-circ.or.jp been reported that plasma ADMA concentrations can become elevated in complicated pregnancies (eg, in preeclampsia)!1

L-homoarginine is a naturally occurring, basic, nonessential cationic amino acid that is believed to be derived from lysine!2 L-homoarginine has been detected in small amounts in all studied body fluids and organs (eg, serum, urine, cerebrospinal fluid, liver, kidney and brain), ${ }^{13-16}$ but its function is not yet clearly resolved. Several functional studies have demonstrated that L-homoarginine, in addition to L-arginine, can act as a substrate for $\mathrm{NO}$ production by $\operatorname{NOS}^{17-19}$ (Fig 1). Thus, L-homoarginine can be considered as an interesting compound for at least 3 reasons. First, L-homoarginine as such may play a role in the regulation of NO release and, like L-arginine, it is known to be a vasodilator ${ }^{20}$ Second, earlier investigations have shown that cationic amino acids can modulate NO production in endothelial cells by altering cellular L-arginine uptake through transport mechanisms ${ }^{2}{ }^{1}$ Third, the level of L-homoarginine has been believed to be unchanged in a number of physiological and pathological conditions, so it has been used as an internal standard in studies evaluating the role of ADMA in a number of pathological conditions including preeclampsia!11,22-26

In this study, we measured the serum concentrations of L-homoarginine and other molecules (eg, L-arginine, ADMA and SDMA) that may influence NO production. We 
A

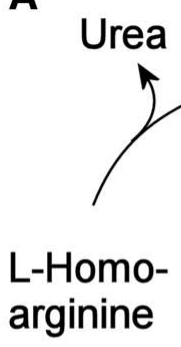

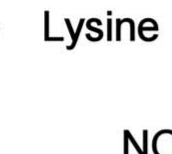
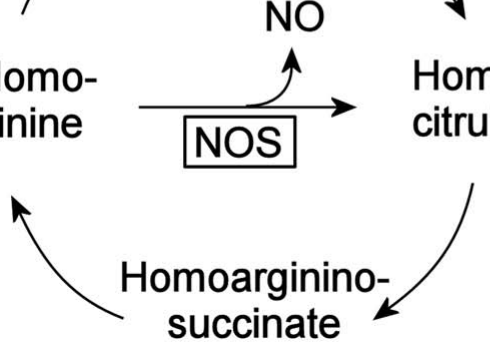

B

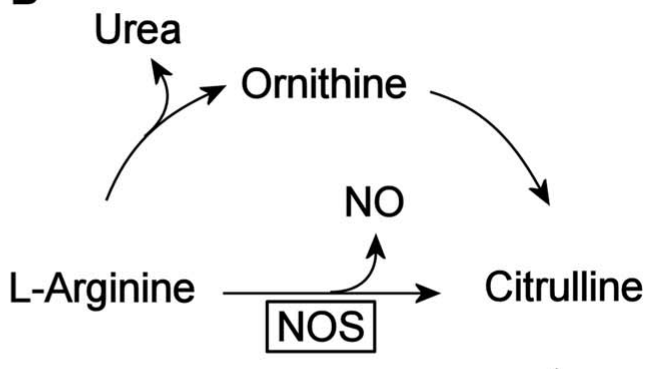

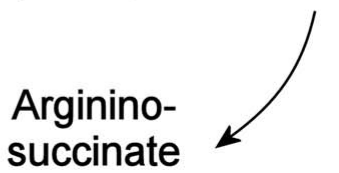

Fig 1. Putative scheme of the parallel biochemical reactions of L-homoarginine (A) and L-arginine (B) in the urea cycle. NO, nitric oxide; NOS, NO synthase.

also investigated the hypothesis that serum L-homoarginine is associated with endothelial function in normal pregnancy.

\section{Methods}

\section{Study Populations}

The normal pregnant control group was derived from The Cardiovascular Risk in Young Finns Study, which is an ongoing 5-center follow-up study of atherosclerosis risk factors in Finnish children and adolescents. The individuals were randomly chosen from a national register, as previously described ${ }^{27}$ There were 3,596 participants in 1980. In the follow-up study in 2001, there were 2,283 participants in the age range $24-39$ years ${ }^{28}$ In this study, we selected all $(n=58)$ healthy pregnant women and non-pregnant control women $(n=63)$ matched for age and smoking status. There were 6 smokers in both groups. Data collected about the menstrual cycle phases of the non-pregnant participants were divided into 4 categories: early follicular phase, late follicular phase, early luteal phase and late luteal phase. In the pregnant group, there were 13 women in the first trimester ( $\leq 14$ weeks), 22 women in the second trimester (15-27 weeks) and 23 women in the third trimester ( $\geq 28$ weeks). These women were examined with a cross-sectional study design to create reference values for the analytes.

The second group belonged to a prospective cohort study that was conducted at the Kuopio University Hospital, Finland. The patients were recruited from the Kuopio University Hospital maternity clinic where they were seen for clinical follow-up through January 2005 to December 2006. In this study, the study subjects with normal uncomplicated pregnancy were seen in the third trimester $(n=15)$ and at 3 months postpartum.

The local ethics committee approved the 2 studies and all patients gave written informed consent before participating in the study.

\section{Blood Samples}

A blood sample was drawn from each subject for Lhomoarginine, L-arginine, ADMA and SDMA assays. The sample was centrifuged at $2,000 \mathrm{~g}$ for $10 \mathrm{~min}$, and the serum was separated and stored frozen at $-70^{\circ} \mathrm{C}$ until analysis.

\section{Measures}

Height and weight were measured, and body mass index
(BMI) was calculated (weight/height ${ }^{2}$ ). Blood pressure was measured with a sphygmomanometer (Hawksley \& Sons Ltd, Lancin, UK). Serum creatinine concentration was measured by photometric Jaffe assay (Olympus Diagnostica $\mathrm{GmbH})$. Glomerular filtration rate was calculated by the Cockcroft-Gault formula.

\section{Vascular Ultrasound Measurements}

Brachial artery FMD was measured by ultrasound according to the guidelines! Ultrasound studies were performed using Sequoia 512 mainframes (Acuson, Mountain View, CA, USA) with $14.0 \mathrm{MHz}$ linear array transducers. The segment of the brachial artery above the antecubital crease was imaged in the longitudinal plane at rest and during reactive hyperemia, induced by a sphygmomanometer cuff, which was placed around the forearm, inflated to a pressure of $250 \mathrm{mmHg}$ and deflated after $4.5 \mathrm{~min}$. End-diastolic (incident with the R-wave) arterial diameter was measured at rest (baseline) and at 40, 60 and $80 \mathrm{~s}$ after cuff release from $5 \mathrm{~s}$ ultrasound image sets. The vessel diameter response in the scans taken after reactive hyperemia was expressed both as the absolute change in diameter (FMD) and as the percentage relative to the resting scan (FMD\%). The 3-month between-visit coefficient of variation was $3.2 \%$ for brachial artery diameter measurements and $26.0 \%$ for FMD measurements.

\section{Assays}

Serum L-homoarginine, L-arginine, ADMA and SDMA levels were determined by high-performance liquid chromatography (HPLC) using precolumn derivatization with o-phthaldialdehyde (OPA, Sigma, St Louis, MO, USA) according to the method described by Teerlink et al ${ }^{29}$ with minor modifications 30 In the HPLC method, the mean recoveries for ADMA, SDMA, L-homoarginine and Larginine from spiked sample were 95, 95, 100 and 113\%, respectively. The intra-assay CVs of the plasma pool for ADMA $(0.643 \mu \mathrm{mol} / \mathrm{L})$, SDMA $(0.654 \mu \mathrm{mol} / \mathrm{L})$, L-homoarginine $(1.2 \mu \mathrm{mol} / \mathrm{L})$ and $\mathrm{L}$-arginine $(58.6 \mu \mathrm{mol} / \mathrm{L})$ were 2.5, 5.6, 1.4 and $2.5 \%(\mathrm{n}=9)$, respectively. Interassay $\mathrm{CVs}$ of 10 series of samples for ADMA, SDMA, L-homoarginine and L-arginine were 4.2, 3.7, 2.9 and $2.8 \%$, respectively?30 $\mathrm{NG}^{\mathrm{G}}$-monomethyl-L-arginine (Fluka, Buchs, Switzerland) was used as an internal standard. 
Table 1 Clinical Characteristics and Serum L-Homoarginine, L-Arg and Dimethylarginine Levels in Non-Pregnant Controls and in the Trimesters of Normal Pregnancy

\begin{tabular}{|c|c|c|c|c|c|}
\hline & $\begin{array}{l}\text { Non-pregnant } \\
\text { controls } \\
(n=61)\end{array}$ & $\begin{array}{c}\text { Trimester I } \\
(n=13)\end{array}$ & $\begin{array}{c}\text { Trimester II } \\
\quad(n=22)\end{array}$ & $\begin{array}{c}\text { Trimester III } \\
(n=23)\end{array}$ & $p$ value \\
\hline Age (years) & $31 \pm 5$ & $29 \pm 4$ & $32 \pm 4$ & $31 \pm 5$ & 0.544 \\
\hline Height $(m)$ & $1.68 \pm 0.06$ & $1.65 \pm 0.05$ & $1.66 \pm 0.06$ & $1.65 \pm 0.07$ & 0.174 \\
\hline Weight $(\mathrm{kg})$ & $66.9 \pm 11.6$ & $65.9 \pm 9.1$ & $70.2 \pm 10.3$ & $75.5 \pm 14.0$ & 0.046 \\
\hline$B M I\left(\mathrm{~kg} / \mathrm{m}^{2}\right)$ & $23.9 \pm 4.5$ & $24.3 \pm 4.3$ & $25.2 \pm 3.4$ & $27.7 \pm 4.4$ & 0.003 \\
\hline Gestation week & & $11 \pm 3$ & $20 \pm 4$ & $31 \pm 3$ & $<0.001$ \\
\hline Systolic $B P(m m H g)$ & $116 \pm 14$ & $111 \pm 10$ & $110 \pm 12$ & $113 \pm 13$ & 0.393 \\
\hline Diastolic BP ( $\mathrm{mmHg})$ & $72 \pm 10$ & $66 \pm 5$ & $64 \pm 7$ & $70 \pm 9$ & 0.003 \\
\hline Cholesterol (mmol/L) & $5.06 \pm 0.90$ & $4.56 \pm 0.71$ & $5.92 \pm 1.03$ & $7.07 \pm 0.94$ & $<0.001$ \\
\hline$H D L-C(\mathrm{mmol} / \mathrm{L})$ & $1.44 \pm 0.30$ & $1.45 \pm 0.30$ & $1.70 \pm 0.24$ & $1.81 \pm 0.42$ & $<0.001$ \\
\hline$L D L-C(\mathrm{mmol} / \mathrm{L})$ & $3.10 \pm 0.84$ & $2.61 \pm 0.45$ & $3.44 \pm 0.67$ & $4.15 \pm 0.83$ & $<0.001$ \\
\hline Triglycerides $(\mathrm{mmol} / \mathrm{L})$ & $1.15 \pm 0.44$ & $1.11 \pm 0.52$ & $1.73 \pm 0.66$ & $2.46 \pm 0.79$ & $<0.001$ \\
\hline Creatinine $(\mu \mathrm{mol} / \mathrm{L})$ & $66 \pm 8$ & $59 \pm 9^{\dagger}$ & $50 \pm 5 *, \dagger$ & $53 \pm 7 *$ & $<0.001$ \\
\hline$G F R(\mathrm{ml} / \mathrm{min})$ & $137 \pm 34$ & $156 \pm 35$ & $190 \pm 39 *, \dot{\dagger}$ & $189 \pm 48 *$ & $<0.001$ \\
\hline Brachial artery diameter $(\mathrm{mm})$ & $3.07 \pm 0.32$ & $3.02 \pm 0.24$ & $3.23 \pm 0.31$ & $3.25 \pm 0.26^{\dagger}$ & 0.019 \\
\hline$F M D(m m)$ & $0.28 \pm 0.12$ & $0.24 \pm 0.09$ & $0.32 \pm 0.14$ & $0.36 \pm 0.17$ & 0.040 \\
\hline$F M D(\%)$ & $9.43 \pm 4.07$ & $7.98 \pm 3.01$ & $10.17 \pm 4.96$ & $11.12 \pm 5.31$ & 0.202 \\
\hline L-homoarginine $(u \mathrm{~mol} / \mathrm{L})$ & $2.7 \pm 1.1$ & $3.1 \pm 1.4$ & $4.8 \pm 1.7 * t \dagger$ & $5.3 \pm 1.5^{*},+$ & $<0.001$ \\
\hline$L-\operatorname{Arg}(\mu \mathrm{mol} / \mathrm{L})$ & $100.6 \pm 17.1$ & $87.1 \pm 11.5^{\dagger}$ & $97.2 \pm 17.2$ & $94.7 \pm 16.1$ & 0.021 \\
\hline$A D M A(\mu \mathrm{mol} / \mathrm{L})$ & $0.577 \pm 0.071$ & $0.513 \pm 0.082$ & $0.518 \pm 0.076^{*}$ & $0.516 \pm 0.064 * *$ & $<0.001$ \\
\hline SDMA $(\mu \mathrm{mol} / \mathrm{L})$ & $0.430 \pm 0.058$ & $0.394 \pm 0.061$ & $0.351 \pm 0.033 *$ & $0.397 \pm 0.056$ & $<0.001$ \\
\hline L-Arg/ADMA ratio & $176.1 \pm 33.3$ & $174.7 \pm 43.7$ & $190.2 \pm 38.2$ & $184.6 \pm 39.1$ & 0.346 \\
\hline ADMA/SDMA ratio & $1.36 \pm 0.19$ & $1.31 \pm 0.15$ & $1.48 \pm 0.20^{\dagger \dagger}$ & $1.31 \pm 0.15^{\#}$ & 0.010 \\
\hline
\end{tabular}

Values are mean $\pm S D$. Data were compared by Mann-Whitney U test with a Bonferroni correction; $p$ value is calculated by KruskallWallis test between all groups.

${ }^{*} p<0.001$ vs control; ${ }^{* *} p<0.01$ vs control; ${ }^{\dagger} p<0.05$ vs control; ${ }^{\dagger} p<0.05$ vs trimester $I ;{ }^{\star} p<0.01$ vs trimester I.

$\$ p<0.05$ vs trimester II; \# $p<0.01$ vs trimester II.

L-Arg, L-arginine; BMI, body mass index; BP, blood pressure; HDL-C, high-density lipoprotein-cholesterol; LDL-C, low-density lipoprotein-cholesterol; GFR, glomerular filtration rate; FMD, flow-mediated dilatation; ADMA, asymmetric dimethylarginine; SDMA, symmetric dimethylarginine.

\section{Statistical Analysis}

Data are presented as mean \pm standard deviation (SD). Comparisons between groups were performed with the Kruskal-Wallis test and the non-parametric Mann-Whitney U-test. Bonferroni correction was used with the MannWhitney U-test for analyte comparisons between different trimesters of pregnancy and the control group. The correlations between L-homoarginine concentration and other analytes were calculated by Spearman correlation coefficient test. In linear regression analysis, the concentration of serum L-homoarginine was log-transformed because of the skewed distribution. In addition, multiple-regression analysis was used to evaluate the independent correlates of FMD\%. A computer software program (SPSS 11.5 for Windows; SPSS Inc, Chicago, IL, USA) was used. A probability level $<0.05$ was considered statistically significant.

\section{Results}

We recorded significant changes in maternal L-homoarginine concentrations during normal pregnancy (Table 1). Serum L-homoarginine concentrations remained unchanged in the first trimester, but significantly increased concentrations were observed in the second and third trimesters as compared with the levels in non-pregnant control women $(4.8 \pm 1.7$ and $5.3 \pm 1.5$ vs $2.7 \pm 1.0 \mu \mathrm{mol} / \mathrm{L}, \mathrm{p}<0.001$ for both, respectively). Likewise, in the second $(\mathrm{p}<0.05)$ and third trimesters $(\mathrm{p}<0.01)$ concentrations of L-homoarginine were higher than during the first trimester. Maternal L-arginine concentrations decreased significantly in the first trimester $(p<0.05)$ and then increased near to the control levels towards term.
L-homoarginine concentrations detected varied between 1.4 and $9.4 \mu \mathrm{mol} / \mathrm{L}$ during pregnancy and between 1.2 and $6.2 \mu \mathrm{mol} / \mathrm{L}$ in the non-pregnant control group. According to the correlation analysis, which included all pregnant women, the L-homoarginine concentration correlated significantly with gestational age $(r=0.426, p=0.001)($ Fig 2A). In addition, both baseline brachial artery diameter and FMD (Fig 2B) were positively correlated with serum L-homoarginine concentration $(\mathrm{r}=0.362, \mathrm{p}=0.006$ and $\mathrm{r}=0.306$, $\mathrm{p}=0.022$, respectively) in pregnant women, but not in nonpregnant females. In the multivariable regression analysis adjusted for brachial artery baseline diameter, FMD\% was significantly associated with L-homoarginine concentration (standardized coefficient $\beta=0.192, \mathrm{p}=0.015$ ). When L-homoarginine, gestational age, total cholesterol and brachial artery baseline diameter were added to the same multivariable model, only brachial artery baseline diameter $(\mathrm{p}<0.007)$ remained significantly associated with FMD\%. After delivery, the concentration of L-homoarginine, the brachial artery diameter and FMD $(2.2 \pm 0.8 \mu \mathrm{mol} / \mathrm{L}, 3.11 \pm 0.32 \mathrm{~mm}$ and $0.22 \pm 0.09 \mathrm{~mm}$, respectively) were comparable to the values in non-pregnant females. L-homoarginine concentrations were not associated with L-arginine or dimethylarginines during pregnancy or in non-pregnant women. In non-pregnant women, FMD parameters, lipids, L-homoarginine, L-arginine and dimethylarginines did not vary significantly during the different phases of the menstrual cycle.

The data summarizing the dimethylarginine concentrations in all trimesters of normal pregnancy are shown in Table 1. The concentrations of ADMA were similar in all trimesters, whereas slight, probably clinically unimportant, biphasic changes were observed in maternal SDMA concen- 
A

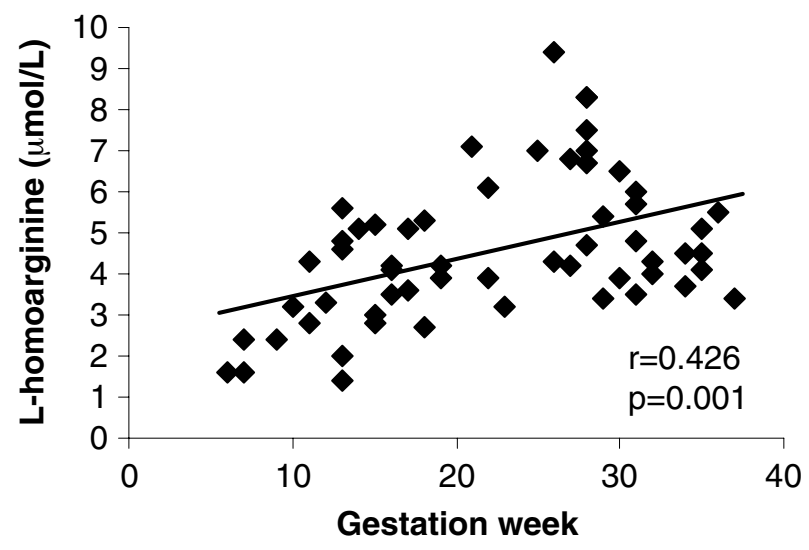

B

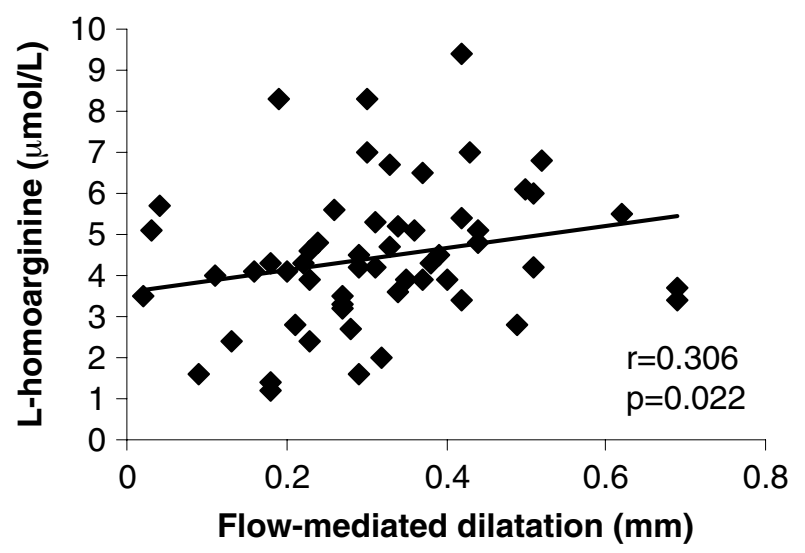

C

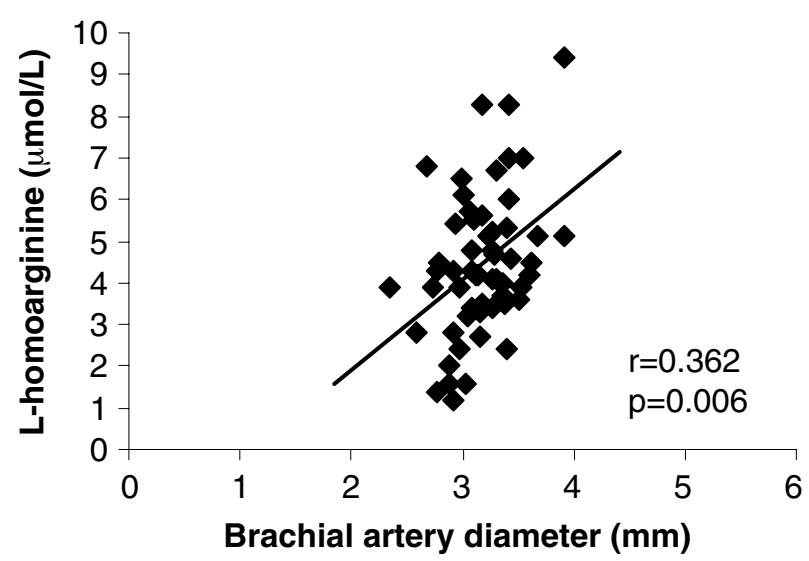

Fig 2. In pregnancy, L-homoarginine concentration correlates positively with (A) gestation duration, (B) flow-mediated vasodilatation and $(C)$ brachial artery diameter $(n=58)$.

trations, with the second trimester level being statistically significantly lower than those for the third trimester or in the non-pregnant state. The L-arginine/ADMA ratio, an indicator of NO production by NOS 31 remained unchanged in all trimesters. The ADMA/SDMA ratio, an index of the ADMA degrading enzyme, dimethylarginine dimethylaminohydrolase activity ${ }^{32}$ displayed a statistically significant increase in the second trimester compared with the ratio in the first and third trimesters $(\mathrm{p}<0.05)$.

\section{Discussion}

The present study demonstrated increased maternal Lhomoarginine concentrations in the second and third trimesters of pregnancy. In addition, we observed that the L-homoarginine concentration was associated with FMD, a non-invasively measured marker of endothelial function. These findings suggest that L-homoarginine has a biological function in normal pregnancy, which may be related endothelial-dependent vasodilatation.

The difference between the pregnant and non-pregnant group in the L-homoarginine concentrations cannot be attributed to intra-individual variability, which was found to be in the order of $14 \%$ in the study of Blackwell et al ${ }^{15}$ where the mean L-homoarginine concentration in the normal population was $1.99 \mu \mathrm{mol} / \mathrm{L}(\mathrm{n}=100)$. They did not find any significant differences in L-homoarginine concentrations between female and male subjects. The mechanism behind our observed elevation of L-homoarginine concentration during pregnancy remains unclear, but the present results imply that an L-homoarginine concentration exceeding $6 \mu \mathrm{mol} / \mathrm{L}$ may be high in a young non-pregnant woman whereas in a pregnant woman such a concentration could be common.

One explanation for the elevated L-homoarginine in pregnancy could be the increased expression of the L-arginine:glycine amidinotransferase gene after its induction by estrogen. Normally, the maternal estrogen concentration increases substantially during pregnancy, and estrogen has been shown to modulate the expression of the L-arginine: glycine amidinotransferase gene ${ }^{33}$ Using an animal model, Ryan et al have shown that this enzyme can convert lysine to L-homoarginine in reactions analogous to those of the urea cycle (Fig 1) in which lysine replaces ornithine in the rat kidney. ${ }^{4}$ Guanidinated amino acids, such as L-homoarginine, are also known to be more stable than lysine when incorporated into proteins 35 One possibility with regard to guanidinated proteins is that the L-homoarginine is being transformed back to lysine by arginase in the liver and kidneys $3{ }^{34}$ thus preventing lysine deficiency ${ }^{36}$

It has been demonstrated that natural hormonal fluctuation during the menstrual cycle may reflect endothelial function, and FMD\% has been shown to decrease in the early luteal phase compared with the follicular phase and increase again in the late luteal phase 37 In the present study we did not measure estrogen or other hormonal levels, so we could not examine the correlation between estrogen and L-homoarginine concentrations or endothelial function parameters. However, there were data for the menstrual cycle phase of non-pregnant participants and these groups were rather evenly divided, although the number of participants in each group was small $(n=10-13)$. A non-significant decreasing trend in FMD\% was found in the early luteal phase group, but lipids, L-homoarginine, L-arginine and dimethylarginines did not vary significantly during the 4 phases of the menstrual cycle.

Normal pregnancy is associated with profound hemodynamic changes, including NO-mediated endothelium-dependent vasodilation? Several functional studies have demonstrated that L-homoarginine, in addition to L-arginine, can act as a substrate for NO production by $\mathrm{NOS}^{17-19,38}$ (Fig 1) and pregnancy is associated with reprogramming of cell signalling in response to the increased consumption of NO ${ }^{39}$ Gerritsen et al have observed L-homocitrulline in the urine of newborns, but not in adults, and NOS enzyme is 
known to convert L-homoarginine to L-homocitrulline releasing $\mathrm{NO}^{40}$ However, kinetic analysis has revealed that L-arginine exhibits a 2-fold faster maximal binding rate to the NOS enzyme than L-homoarginine, 38 and there is a huge excess of L-arginine in circulation, so the functional role of L-homoarginine might be of only minor importance in NOdependent endothelium-derived vasodilatation.1 ${ }^{4}$ On the other hand, very low ADMA levels are believed to inhibit NOS activity by competing with the substrate L-arginine when the concentration of L-arginine is several 100 -fold higher than the concentration of ADMA. In addition, earlier investigations have shown that cationic amino acids can modulate NO production in endothelial cells by altering cellular L-arginine transport through transport mechanisms. ${ }^{21}$

We could not find any association between the maternal L-homoarginine concentration and the ADMA or SDMA concentration, and it is likely that the physiological concentration of L-homoarginine is not a key regulator of ADMA and SDMA. Because L-homoarginine is widely used as an internal standard in medical studies when measuring the serum or plasma level of L-arginine, ADMA or SDMA by HPLC, this increase in the L-homoarginine concentration during pregnancy should be kept in mind to avoid erroneous results.

In a recent study, it was observed that the whole-body NO synthesis rate was reduced and FMD $\%$ was $36 \%$ lower in healthy volunteers with hypercholesterolemia compared with controls, although there were no differences in the plasma ADMA concentrations between the hyper- and normocholesterolemic participants. ${ }^{42}$ We have previously shown in the Young Finns cohort study that ADMA is inversely related to brachial $\mathrm{FMD}_{4}^{43}$ we have also compared the changes in the lipid concentrations and the concentrations of L-arginine, ADMA and SDMA and FMD in normal pregnant women and healthy non-pregnant controls ${ }^{44}$ In the present study, ADMA, SDMA and L-arginine concentrations were decreased in normal pregnancy, despite marked hypercholesterolemia, and they were not correlated with FMD. Regardless of hypercholesterolemia, the FMD values were concomitantly enhanced towards the end of pregnan$\mathrm{cy} 45$

\section{Study Limitations}

There is a large long-term variation found in FMD measurements, although the long-term reproducibility of brachial artery diameter measurements is excellent ${ }^{43}$ In our HPLC assay, the intra-assay and interassay variations of L-arginine, dimethylarginines and L-homoarginine were low? Our study population belongs to a retrospective non-longitudinal study and has the flaws of a small cross-sectional study. In addition, several physiologic, metabolic and immunologic changes, which interact with each other, take place in the maternal body during normal pregnancy. Thus, when statistical significance is measured by multivariable models, it may, however, reflect overcorrection, because there are strong correlations between the included parameters. In addition, when evaluating the results, it is important to notice that correlation analysis in cross-sectional studies demonstrates associations between analytes that do not necessarily imply causality.

In summary, the present results reveal that the L-homoarginine concentration increases significantly in the second and third trimesters of normal pregnancy and may contribute to enhanced endothelial function.

\section{Acknowledgments}

The authors would like to thank Mrs Raija Isomäki for skilful technical assistance and Docent Reijo Laaksonen for valuable comments to the manuscript. This study was supported by grants from Kuopio University Hospital (grant no. 15863 and EVO grant no.5190 and 5031320), EVOgrants from Turku and Academy of Finland (grant no. 77841 and 210283), Social Insurance Institution and The Finnish Foundation for Cardiovascular Research.

\section{References}

1. Corretti MC, Anderson TJ, Benjamin EJ, Celermajer D, Chardonneau F, Creager MA, et al. Guidelines for the ultrasound assessment of endothelial-dependent flow-mediated vasodilatation of the brachial artery: A repost of the international brachial artery reactivity task force. J Am Coll Cardiol 2002; 39: 257-265.

2. Neunteufl T, Katzenschlager R, Hassan A, Klaar U, Schwarzacher S, Glogar D, et al. Systemic endothelial dysfunction is related to the extent and severity of coronary artery disease. Atherosclerosis 1997; 129: $111-118$.

3. Chan SY, Mancini GB, Kuramoto L, Schulzer M, Frohlich J, Ignaszewski A. The prognostic importance of endothelial dysfunction and carotid atheroma burden in patients with coronary artery disease. J Am Coll Cardiol 2003; 42: 1037-1043.

4. Benjamin EJ, Larson MG, Keyes MJ, Mitchell GF, Vasan RS, Keaney JF Jr, et al. Clinical correlates and heritability of flow-mediated dilation in the community: The Framingham Heart Study. Circulation 2004; 109: 613-619.

5. Kirma C, Akcakoyun M, Esen AM, Barutcu I, Karakaya O, Saglam $\mathrm{M}$, et al. Relationship between endothelial function and coronary risk factors in patients with stable coronary artery disease. Circ J 2007; 71: $698-702$.

6. Grönroos P, Raitakari OT, Kähönen M, Hutri-Kähönen N, Juonala $\mathrm{M}$, Marniemi J, et al. Relation of apolipoprotein E polymorphism to markers of early atherosclerotic changes in young adults: The Cardiovascular Risk in Young Finns Study. Circ J 2008; 72: 29-34.

7. Dørup I, Skajaa K, Sørensen KE. Normal pregnancy is associated with enhanced endothelium-dependent flow-mediated vasodilatation. Am J Physiol Heart Circ Physiol 1999; 276: 821-825.

8. Cockell AP, Poston L. Flow mediated vasodilatation is enhanced in normal pregnancy but reduced in pre-eclampsia. Hypertension 1997; 30: $247-251$.

9. McVeigh GE, Brennan GM, Johnston GD, McDermott BJ, McGrath LT, Henry WR, et al. Impaired endothelium-dependent and independent vasodilation in patients with type 2 (non-insulin-dependent) diabetes mellitus. Diabetologia 1992; 35: 771-776.

10. Holden DP, Fickling SA, Whitley GS, Nussey SS. Plasma concentrations of asymmetric dimethylarginine, a natural inhibitor of nitric oxide synthase, in normal pregnancy and preeclampsia. Am J Obstet Gynecol 1998; 178: $551-556$.

11. Savvidou MD, Hingorani AD, Tsikas D, Frölich JC, Vallance P, Nicolaides KH. Endothelial dysfunction and raised plasma concentrations of asymmetric dimethylarginine in pregnant women who subsequently develop pre-eclampsia. Lancet 2003; 361: 1511-1517.

12. Ryan WL, Wells IC. Homocitrulline and homoarginine synthesis from lysine. Science 1964; 144: 1122-1127.

13. Mori A, Watanabe Y, Fujimoto N. Fluorometrical analysis of guanidino compounds in human cerebrospinal fluid. J Neurochem 1982; 38: $448-450$.

14. Marescau B, Deshmukh DR, Kockx M, Possemiers I, Qureshi IA, Wiechert P, et al. Guanidino compounds in serum, urine, liver, kidney, and brain of man and some ureotelic animals. Metabolism 1992; 41: $526-532$.

15. Blackwell S, O'Reilly DS, Talwar D. Biological variation of asymmetric dimethylarginine and related arginine metabolites and analytical performance goals for their measurement in human plasma. Eur $J$ Clin Invest 2007; 37: 364-371.

16. Meinitzer A, Puchinger M, Winklhofer-Roob BM, Rock E, Ribalta J, Roob JM, et al. Reference values for plasma concentrations of asymmetrical dimethylarginine (ADMA) and other arginine metabolites in men after validation of a chromatographic method. Clin Chim Acta 2007; 384: $141-148$.

17. Hecker M, Walsh DT, Vane JR. On the substrate specificity of nitric oxide synthase. FEBS Lett 1991; 294: 221 -224.

18. Chen PY, Sanders PW. Role of nitric oxide synthesis in salt-sensitive hypertension in Dahl/Rapp rats. Hypertension 1993; 22: 812-818.

19. Hrabak A, Bajor T, Temesi A. Comparison of substrate and inhibitor specificity of arginase and nitric oxide (NO) synthase for arginine analogues and related compounds in murine and rat macrophages. 
Biochem Biophys Res Commun 1994; 198: 206-212.

20. Bhardwaj R, Moore PK. The effect of arginine and nitric oxide on resistance blood vessels of the perfused rat kidney. Br J Pharmacol 1989; 97: 739-744.

21. Kakoki M, Kim HS, Edgell CJ, Maeda N, Smithies O, Mattson DL. Amino acids as modulators of endothelium-derived nitric oxide. Am J Physiol Renal Physiol 2006; 291: F297-F304.

22. Chan JR, Böger RH, Bode-Böger SM, Tangphao O, Tsao PS, Blaschke TF, et al. Asymmetric dimethylarginine increases mononuclear cell adhesiveness in hypercholesterolemic humans. Arterioscler Thromb Vasc Biol 2000; 20: 1040 - 1046.

23. Böger RH, Lentz SR, Bode-Böger SM, Knapp HR, Haynes WG. Elevation of asymmetrical dimethylarginine may mediate endothelial dysfunction during experimental hyperhomocyst(e)inaemia in humans. Clin Sci (Lond) 2001; 100: 161-167.

24. Pi J, Kumagai Y, Sun G, Shimojo N. Improved method for simultaneous determination of L-arginine and its mono- and dimethylated metabolites in biological samples by high-performance liquid chromatography. J Chromatogr B Biomed Sci Appl 2000; 742: 199-203.

25. Wahbi N, Dalton RN, Turner C, Denton M, Abbs I, Swaminathan R. Dimethylarginines in chronic renal failure. J Clin Pathol 2001; 54: $470-473$.

26. Mittermayer F, Mayer BX, Meyer A, Winzer C, Pacini G, Wagner $\mathrm{OF}$, et al. Circulating concentrations of asymmetrical dimethyl-Larginine are increased in women with previous gestational diabetes. Diabetologia 2002; 45: 1372-1378.

27. Åkerblom HK, Viikari J, Uhari M, Räsänen L, Byckling T, Louhivuori $\mathrm{K}$, et al. Atherosclerosis precursors in Finnish children and adolescents. I: General description of the cross-sectional study of 1980, and an account of the children's and families' state of health. Acta Paediatr Scand Suppl 1985; 318: 49-63.

28. Juonala M, Viikari JS, Hutri-Kähönen N, Pietikäinen M, Jokinen E, Taittonen L, et al. The 21-year follow-up of the Cardiovascular Risk in Young Finns Study: Risk factor levels, secular trends and east-west difference. J Intern Med 2004; 255: 457-468.

29. Teerlink T, Nijveldt RJ, de Jong S, van Leeuwen PA. Determination of arginine, asymmetric dimethylarginine, and symmetric dimethylarginine in human plasma and other biological samples by highperformance liquid chromatography. Anal Biochem 2002; 303: 131 137.

30. Valtonen P, Karppi J, Nyyssönen K, Valkonen VP, Halonen T, Punnonen K. Comparison of HPLC method and commercial ELISA assay for asymmetric dimethylarginine (ADMA) determination in human serum. J Chromatogr B Anal Technol Biomed Life Sci 2005; 828: $97-102$.

31. Tsikas D, Sandmann J, Savva A, Luessen P, Böger RH, Gutzki FM, et al. Assessment of nitric oxide synthase activity in vitro and in vivo by gas chromatography-mass spectrometry. J Chromatogr B Biomed Sci Appl 2000; 742: 143-153.
32. Leiper J, Vallance P. Biological significance of endogenous methylarginines that inhibit nitric oxide synthases. Cardiovasc Res 1999; 43: $542-548$.

33. Zhu Y, Evans MI. Estrogen modulates the expression of L-arginine: Glycine amidinotransferase in chick liver. Mol Cell Biochem 2001; 221: $139-145$.

34. Ryan WL, Johnson RJ, Dimari S. Homoarginine synthesis by rat kidney. Arch Biochem Biophys 1969; 131: 521-526.

35. Cupo P, El-Deiry W, Whitney PL, Awad WM Jr. Stabilization of proteins by guanidination. J Biol Chem 1980; 255: 10828-10833.

36. Angkanaporn K, Ravindran V, Mollah Y, Bryden WL. Homoarginine influences voluntary feed intake, tissue basic amino acid concentrations and arginase activity in chickens. J Nutr 1997; 127: $1128-$ 1136.

37. Williams MRI, Westerman RA, Kingwell BA, Paige J, Blombery PA, Sudhir K, et al. Variations in endothelial function and arterial compliance during the menstrual cycle. J Clin Endocrinol Metab 2001; 86: $5389-5395$

38. Abu-Soud HM, Wang J, Rousseau DL, Stuehr DJ. Stopped-flow analysis of substrate binding to neuronal nitric oxide synthase. Biochemistry 1999; 38: 12446-12451.

39. Yi FX, Magness RR, Bird IM. Simultaneous imaging of [Ca2+]i and intracellular NO production in freshly isolated uterine artery endothelial cells: Effects of ovarian cycle and pregnancy. Am J Physiol Regul Integr Comp Physiol 2005; 288: R140-R148.

40. Gerritsen T, Lipton SH, Strong FM, Waisman HA. On the isolation and identification of homocitrulline from urine. Biochem Biophys Res Commun 1961; 4: 379-383.

41. Bird IM, Zhang L, Magness RR. Possible mechanisms underlying pregnancy-induced changes in uterine artery endothelial function. Am J Physiol Regul Integr Comp Physiol 2003; 284: R245-R258.

42. Maas R, Schwedhelm E, Kahl L, Li H, Benndorf R, Lüneburg N, et al. Simultaneous assessment of endothelial function, nitric oxide synthase activity, nitric oxide-mediated signaling, and oxidative stress in individuals with and without hypercholesterolemia. Clin Chem 2008; 54: 292-300.

43. Juonala M, Viikari, JSA, Alfthan G, Marniemi J, Kähönen M, Taittonen L, et al. Brachial artery flow-mediated dilatation and asymmetrical dimethylarginine in the Cardiovascular Risk in Young Finns Study. Circulation 2007; 116: 1367-1373.

44. Saarelainen H, Valtonen P, Punnonen K, Laitinen T, Raitakari OT, Juonala M, et al. Subtle changes in ADMA and L-arginine concentrations in normal pregnancies are unlikely to account for pregnancyrelated increased flow-mediated dilatation. Clin Physiol Funct Imaging 2008; 28: 120-124.

45. Saarelainen $\mathrm{H}$, Laitinen $\mathrm{H}$, Raitakari OT, Juonala M, Heiskanen N, Lyyra-Laitinen T, et al. Pregnancy-related hyperlipidemia and endothelial function in healthy women. Circ J 2006; 70: 768-772. 